\title{
INDICADORES PADRONIZADOS DE GESTÃO NO PLANEJAMENTO ORÇAMENTÁRIO MUNICIPAL
}

\author{
OLIVEIRA, Gecileno Luiz de(1); MARTINELLI, Flavia Regina Bianchi(2)
}

(1) Especialista em Gestão Pública, Centro de Referência em Formação e em Educação à Distância CEFOR, Instituto Federal do Espírito Santo IFES, campus Colatina. http://lattes.cnpq.br/4757221961941716

(2)Professor Orientador. Mestre em Engenharia Civil, Centro de Referência em Formação e em Educação à Distância CEFOR, Instituto Federal do Espírito Santo IFES, campus Colatina. E-mail: flavia.vix@ifes.edu.br

\section{RESUMO}

O presente estudo propõe analisar a viabilidade de utilização de indicadores padronizados de gestão aplicados ao processo de planejamento do orçamento municipal. Partindo da análise da literatura existente sobre o tema para subsidiar a validade da utilização de índices como medida de desempenho das organizações governamentais, a pesquisa pretende demonstrar a possibilidade de construção e utilização de indicadores padrão como forma de mensuração da execução dos programas de governo para estruturas administrativas de nível federativo municipal - as quais notoriamente dispõem de menores condições técnicas, humanas e tecnologias para a implantação de sistemas de acompanhamento e controle gerenciais de resultados de processos e produtos. Ao largo da parca existência de literatura científica sobre administração pública municipal, o estudo pretende demonstrar a oportunidade da utilização de indicadores padronizados como forma incipiente de implantação dos referidos sistemas de monitoramento da gestão.

Palavras - chave: administração pública; orçamento-programa; planejamento público; indicadores de desempenho; município.

\section{INTRODUÇÃO}

As recentes mudanças sociais têm promovido impactos diretos sobre as organizações. Dessa forma, tanto a gestão empresarial quanto o setor público têm se deparado com a necessidade de mensurar e avaliar o resultado de suas ações.

Tais resultados são medidos pela racionalidade alocativa de recursos. Para a administração geral, esse resultado é percebido pela geração de lucros econômicos. Já para a administração do setor público, os resultados são medidos também por critérios de eficácia e de impactos sobre a sociedade.

A necessidade de avaliação e demonstração dos resultados da aplicação de recursos públicos advindos do orçamento-programa oportuniza o desenvolvimento de estudos científicos e acadêmicos sobre os temas de evidenciação patrimonial e transparência orçamentária. 
Tal necessidade tem por condão, ainda, trazer à ciência contábil o seu papel de instrumento gerencial para tomada de decisões, servindo como suporte de geração de informações para a administração pública.

Ainda o presente estudo abrevia o hiato acadêmico existente sobre a administração municipal, tema preterido em contraponto às pesquisas sobre processos governamentais federais, conforme percebem Oliveira e Poubel da Silva (2012) em estudo sobre as relações institucionais entre poderes executivo e legislativo locais em matéria de planejamento orçamentário.

Da mesma forma, busca preencher lacuna existente sobre avaliação de resultados, cuja vertente de estudos é sobrepujada por temas acerca de processos de elaboração e de formulação de agendas e políticas públicas (RAMOS e SCHABBACH, 2012, p. 1273).

O objetivo geral do estudo é a investigação sobre a viabilidade de utilização de indicadores padronizados de desempenho, aplicáveis ao processo de planejamento e orçamento no âmbito de pequenos e médio municípios - estes definidos segundo o critério populacional utilizado pela constituição federal vigente e direito administrativo contemporâneo.

Por objetivos específicos, o estudo pretende:

- comprovar a inserção da administração pública no campo administrativo geral;

- estabelecer a correlação entre administração empresarial e de governo;

- $\quad$ estabelecer a diferenciação entre ambas as administrações;

- propor conceitos e instrumentos de gestão como ferramentas aplicáveis a ambos os universos administrativos;

- estabelecer aplicação prática de elaboração e utilização de indicadores de desempenho para a administração de municípios de pequeno e médio porte conforme o critério populacional utilizado pelo Direito Administrativo; e

- perceber os impactos da referida prática sobre o sistema de gestão e sobre as pessoas envolvidas no processo de orçamento-programa. 
O estudo considera a realidade dos municípios enquanto "última divisão físicoterritorial da organização federativa" (REZENDE e CASTOR, 2005, p. 5). Por consequência, dotados de menores capacidades tecnológica, científica e estrutural. Estes entes federativos possuem especificidades individuais, mas também características grupais similares. Por exemplificação, Kerbauy (2005, p. 338) aponta que, para os municípios criados a partir da promulgação da Carta Federal de 1988, noventa por cento possuem menos de cinquenta mil habitantes e oitenta por cento de suas despesas são cobertas por transferências institucionais (repasse de recursos da União e dos Estados para os Municípios).

Nesse contexto, aos municípios de pequeno e médio porte segundo critério populacional, podem ser propostos estudos e soluções que os permitam aproximarse, em capacidade de gestão, aos demais níveis da federação. O momento atual pelo qual passa a gestão pública (BRASIL, 2010, p. 5), em sua necessidade de fornecer respostas à sociedade, torna oportuno e útil o desenvolvimento da presente pesquisa.

A intersecção entre o campo acadêmico e o campo profissional, ademais, concretiza o surgimento de soluções pragmáticas e desenvolve o conhecimento diretamente aplicável à administração, sendo esta também justificativa para a presente peça científica.

\section{REFERENCIAL TEÓRICO}

A sobrevivência das organizações, sobretudo em cenários econômicos sujeitos a efeitos de constantes alterações, depende de sistemas e metodologias que forneçam ao gestor informações necessárias à tomada de decisões. 0 conhecimento do resultado das ações empreendidas pela organização, bem como dos processos internos, propicia aos diversos níveis da organização executar ações planejadas e em consonância com os resultados pretendidos pela gestão.

A geração de informações aos diversos níveis e usuários da organização deve ser feita de maneira segura e metodológica, de forma que os resultados apurados reflitam a realidade organizacional. Nesse contexto, a utilização de indicadores como ferramentas de planejamento e gestão mostra-se imprescindível, seja para as 
organizações da iniciativa privada ou para as do setor público.

Indicadores são unidades de medidas para atividades ou processos considerados relevantes para a organização. Refletem o momento em que são apurados e permitem avaliar de forma periódica e comparativa os resultados, tendo por parâmetro uma base de referência inicialmente estabelecida.

Possuem por característica a capacidade de evidenciar situações ou fenômenos não imediatamente perceptíveis por empirismo - por isso, a tarefa primordial de um indicador ou sistema de indicadores é expressar de forma clara e inteligível a situação que se pretenda analisar.

O resultado do indicador deve prover informações para a tomada de decisões sejam estas de caráter operacional, tático ou estratégico conforme a natureza das informações possibilitadas pelo índice (REIS e MACHADO JR, 2012; CAMARGO apud SILVA e CAVALCANTI, 2005; GRATERON, 1999; FERNANDES, 2004). Logo, os indicadores são utilizados para controlar e melhorar a qualidade e o desempenho de produtos e processos.

\subsection{INDICADORES E SISTEMAS DE PROCESSAMENTO ORGANIZACIONAL}

Toda empresa possui um sistema de processamento - composto por entrada de insumos, por processos internos e por produtos finais, cujo objetivo é a entrega de um bem ou serviço para o cliente. Um sistema de medição consiste em indicadores para medir cada uma das unidades: entrada, processamento e saída.

A interação ou análise conjunta dos indicadores dessas etapas horizontais compõe a essência de um sistema de medição, permitindo o uso aprofundado e inteligente para a verificação das causas e efeitos e o fornecimento de informações para facilitar as decisões no processo de gestão (FERNANDES, 2004, p. 11 - 12).

Por gestão, entende-se o ato de administrar - o qual envolve tomada de decisões. Para o setor público corresponde a cuidar de bens alheios ao gestor e à entidade, recolhendo impostos e fornecendo serviços e obras de caráter público de forma a não provocar desequilíbrios entre a capacidade de geração de receitas e de assunção de despesas (GRATERON, 1999, p.1). 
A gestão pública, na visão de Ribeiro (2013, p. 7) corresponde às funções e princípios aplicáveis ao planejamento, implantação, execução e controle de políticas públicas - voltadas tanto para o fornecimento de bens e serviços à população, quanto para a manutenção da capacidade de funcionamento da administração. Segue o autor preconizando que as políticas públicas são o resultado ou produto do processamento das demandas sociais - estas são os insumos do sistema, sendo processadas como problemas sociais a serem impactados pela atuação governamental e tendo por resultado as políticas públicas.

A comparação entre o processo produtivo de organizações privadas e públicas, bem como a utilização de sistemas de indicadores para medição de resultados pode ser visualizada pela Figura 1.

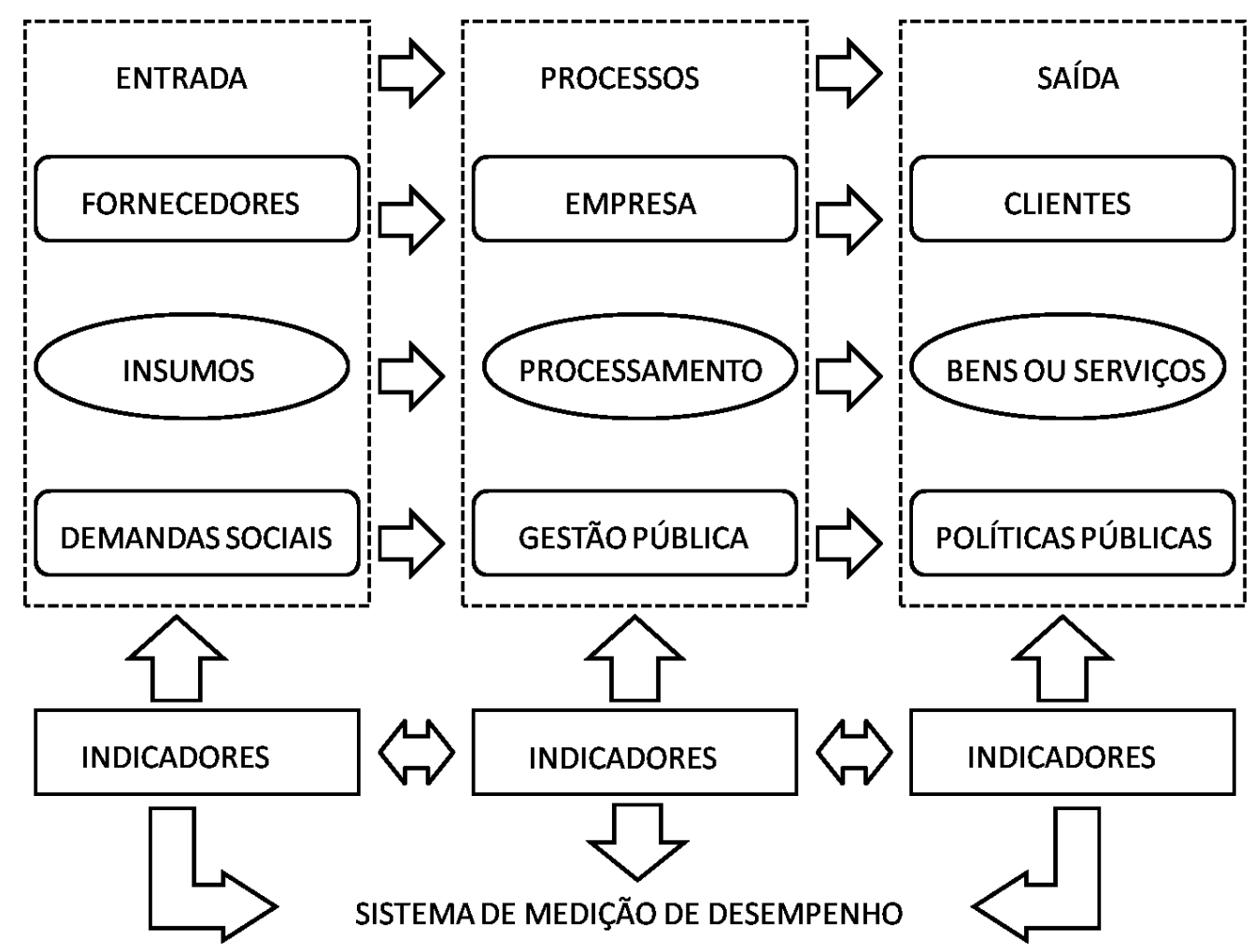

Figura 1: Sistema Produtivo Primário das Organizações e Sistemas de Indicadores Fonte: Adaptado de Fernandes (2004, p.11)

\subsection{SISTEMAS DE INDICADORES, PLANEJAMENTO E GESTÃO}

À medida que os indicadores são correlacionados e analisados em conjunto, o sistema de indicadores resultante provê informações para níveis organizacionais 
verticalizados. Dessa forma, o nível de execução ou operacional utiliza indicadores de etapas de processos.

Pelo agrupamento dos indicadores operacionais, são originados indicadores táticos - utilizados para a tomada de decisões de cunho gerencial intermediário sobre produtos, serviços, fornecedores e clientes. A partir de tais dados, são originados os indicadores de nível estratégico - os quais apontam a performance da organização no ambiente externo e frente à organizações concorrentes ou similares (FERNANDES, 2004, p. 13). Esta última comparação é utilizada sobretudo em organizações públicas, haja vista a característica não mercantil das mesmas.

Kaplan e Norton citados por Fernandes (2004, p. 13) apresentam alternativo sistema classificatório e de construção de indicadores, pelo qual a ação humana é considerada a iniciante do processo de medição - estabelecendo como princípio da boa gestão a disponibilização de condições de atuação profícua e motivada dos funcionários, esta gerando resultados benéficos diretos no retorno sobre o capital investido na companhia (resultado financeiro da empresa).

O conceito de inteligência organizacional, derivado desta consideração do fator humano nas organizações, pode ser estendido à administração pública e leva em conta a capacidade das pessoas em resolver problemas, conviver socialmente e no "saber fazer" - considerando, portanto, os lados social e profissional (REZENDE e CASTOR, 2005, p.28).

O planejamento ancora-se na racionalidade de distribuição de recursos, estabelecendo metas e prioridades de aplicação. Tal processo é comum tanto às organizações privadas quanto às públicas - diferindo apenas na percepção do gestor do que seja "racionalidade".

Para a gestão empresarial, a racionalidade funda-se na obtenção do maior lucro conforme possibilite o jogo econômico. Já para o setor público, com objetivos multíplices, a racionalidade contempla critérios que envolvem julgamentos de resultados, valores e impactos sociais - extrapolando a pura e simples busca pela maior utilidade econômica. (REZENDE e CASTOR, 2005, p. 6 - 7; GRATERON, 1999, p. 2)

As demandas sociais necessitam ser processadas como problemas e que estes 
devem ser expressos por meio de descrição objetiva acompanhada de indicadores de modo geral expressando relação entre duas ou mais variáveis (taxas e quocientes, por exemplo) (RIBEIRO, 2013, p.7).

A formulação de indicadores permite transpor o campo prospectivo de cenários econômicos para o campo operacional de execução.

Nesse sentido, Martins (2004, p. 30 - 31) determina que o processo de gestão seja sintetizado como uma atividade de controle do desempenho de forma integrada para garantir o cumprimento da missão e continuidade da organização. Esse processo de gestão contempla a forma como a organização deverá atingir os objetivos, sendo constituído pelo planejamento de cada unidade da organização e de seus níveis de hierarquia por ações em prazos ao longo do tempo. $O$ autor conceitua planejamento como um processo antecipado de decisão e que pode ser entendido como o resultado de um conjunto de ações organizadas para o cumprimento de uma meta.

Dessa forma, o planejamento como processo de gestão pode ser integrado por quatro níveis, sendo:

- planejamento estratégico como primeira fase no qual são projetadas linhas mestras de ação estratégica conforme cenário vislumbrado;

- planejamento operacional como segunda fase para o qual as diretrizes estratégicas são traduzidas em planos quantificáveis ou conjunto de operações para provocar ou otimizar resultados em curto, médio e longo prazos (nesta fase são quantificados os planos, elaborados os orçamentos e as programações econômicas);

- execução como terceira fase no qual cada gestor identifica as alternativas e implementa as transações aprovadas no orçamento; e

- controle como quarta fase, para a qual são confrontados os resultados obtidos e os projetados, sendo identificadas possíveis necessidades de realinhamento de rumos.

No mesmo sentido, Frezzatti et al.(2007, p.39), Rezende e Castor (2005, p. 101 104) discorrem sobre os níveis de controle como estratégico, táticos e operacionais inclusive como meio de identificação da factabilidade dos objetivos estratégicos iniciais. Os autores apontam a utilização de indicadores como ferramenta do sistema de controle da organização. 
Hronec citado por Martins (2004, p. 40) acrescenta que as medidas de desempenho comunicam as estratégias para baixo, os resultados dos processos para cima e o controle e melhoria dentro dos processos.

Por isso, os indicadores devem ser desenvolvidos de cima para baixo, de forma a interligar as estratégias, os recursos e os processos.

Por consequência, a medição de desempenho deve quantificar o quanto as atividades dentro dos processos ou o quanto os resultados produzidos conseguem atingir da meta preestabelecida (Figura 2).
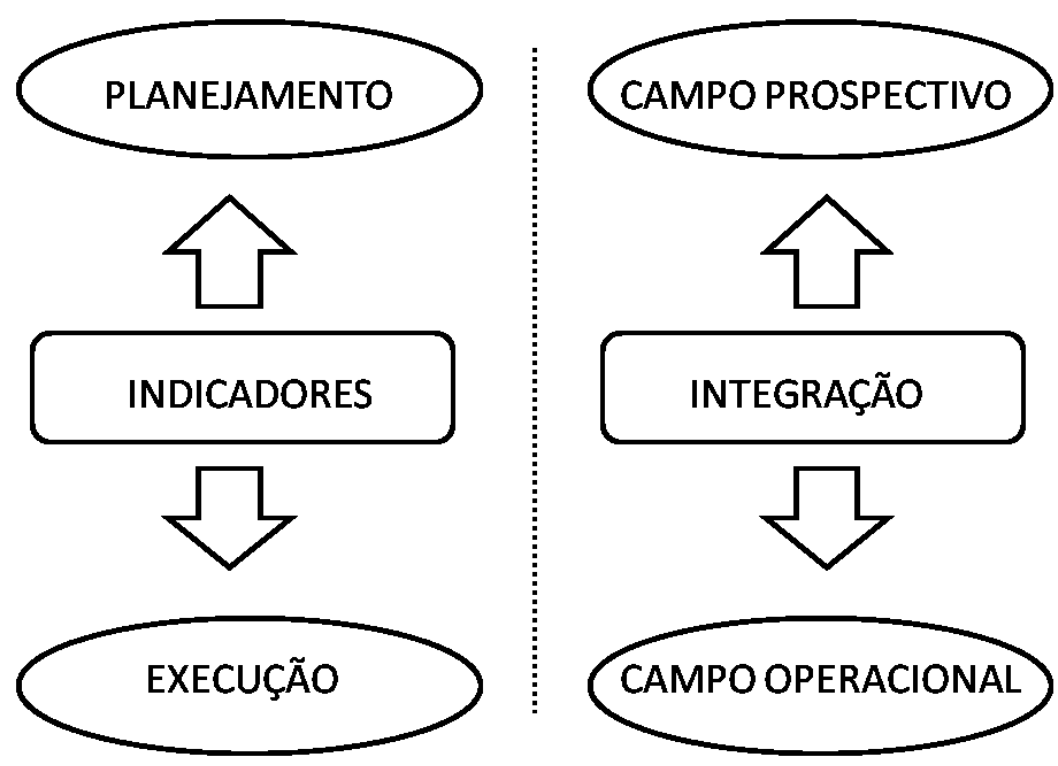

Figura 2: Função dos indicadores para os níveis de planejamento. Fonte: Elaborado pelo autor

\subsection{ORGANIZAÇÕES PÚBLICAS E INDICADORES DE DESEMPENHO}

Grateron (1999, p. 3) é taxativo ao dispor que a gestão pública precisa de sistemas de medição de desempenho para ser avaliada e dar respostas ao cidadão sobre o grau de adequação/aderência das tomadas de decisão dos gestores em relação à eficiência, eficácia e economia dos recursos públicos estabelecidos nos planos e orçamentos.

O mesmo autor fundamenta seu pensamento na percepção de necessidade de um modelo de contabilidade voltada à tomada de decisão e que possibilite a existência de indicadores de gestão adequados aos processos organizacionais.

Silva e Cavalcanti (2005, p. 4) definem que o gerenciamento eficaz da organização 
somente é possível por meio de sistema de medição apoiada em indicadores associados aos objetivos - sendo estes ferramenta imprescindível para o sucesso do empreendimento. Tais indicadores necessitam estar fundados em medições corretas, oportunas e fidedignas para que não conduzam à visões distorcidas da realidade.

O sucesso de um sistema de indicadores impacta diretamente e positivamente o sucesso organizacional, promovendo efeitos positivos sobre a motivação humana dos colaboradores da organização - os quais são elementos importantes na composição da capacidade organizacional de inovar e resolver problemas com foco no usuário. (MARTINS, 2004; FERNANDES, 2004; SILVA e CAVALCANTI, 2005; REZENDE e CASTOR, 2005).

\subsection{INFORMAÇÃO E SISTEMAS DE CONTROLE}

Para o êxito na medição por indicadores, faz-se necessária a existência de um sistema de informações organizacional.

Por informação conceitua-se um dado qualquer com valor/significado a ele atribuído, passando a ter o mesmo um sentido natural e lógico para o usuário -sendo, por isso mesmo, dotado de utilidade. Toda e qualquer informação específica pode ser chamada de "informação personalizada". De mesma forma, o dado útil, de qualidade inquestionável e antecipado pode ser chamado de "informação oportuna".

A informação trabalhada por pessoas (ou por recursos digitais) e que possibilitam a geração de cenários, de simulações ou de oportunidades pode ser chamada de "conhecimento". São concretizadas, portanto, por percepções humanas ou por inferências computacionais. (REZENDE, 2007, p. 508).

Por sistema de informação pode ser entendido cada unidade ou conjunto de partes que geram informações para o sistema de controle da organização (REZENDE e CASTOR, 2005, p. 108).

Cruz Silva apud Silva e Cavalcanti (2005, p.4) estabelecem que:

[...]os mecanismos de controle representam o elemento essencial para assegurar que o governo atinja os objetivos estabelecidos nos programas 
de longa duração com eficiência, efetividade e dentro dos preceitos legais de ordem democrática.

Grateron (1999, p. 7) concebe controle como ação preventiva e corretiva contida em cada uma das fases do processo de cada organização, sendo muito mais complexo no setor público. $O$ controle envolve um conjunto de instrumentos e técnicas de diagnósticos e de análises que permite avaliar a gestão dos agentes que exercem a administração pública.

Nesse sentido, a importância e a necessidade de planejamento das ações têm ocupado espaço na agenda pública - seja como meio de controle fiscal, de equilíbrio das contas públicas ou como meio de transparência da gestão (buscando esta promover o caráter participativo da população na elaboração e no controle da administração pública).

\subsection{PLANEJAMENTO PÚBLICO E ORÇAMENTO DE GOVERNO}

A prática do planejamento nas esferas públicas é apontada como meio indispensável à gestão para, inclusive, promover a modernização da administração, combater antigas mazelas disfuncionais burocráticas e possibilitar a ação em cenários abalados por flutuações econômicas e por crescentes demandas sociais (ANDRADE, 2008, p. 1; REIS e MACHADO JR, 2012, p.1; OLIVEIRA, 2006).

O atual sistema de planejamento público é integrado ao orçamento de governo - por isso o ciclo de planejamento de médio prazo da administração é um processo de planejamento orçamentário. Nesse sentido, a resolução de problemas sociais é alvo de objetivos a serem atingidos por meio de conjuntos organizados de ações e mensuráveis por indicadores, através de metas e prioridades conforme a situação econômica de cada exercício financeiro anual e para os quais fontes de recursos são associadas a objetos de despesa. (OLIVEIRA, 2006)

A concepção do orçamento como um instrumento gerencial de trabalho deve, pois, fazer-se presente na visão moderna de administração pública - interligando os sistemas de planejamento, político-administrativo e financeiro (REIS e MACHADO JR, 2012, p. 2; OLIVEIRA, 2006, p. 59 e 75). 
Andrade (2008, p. 5), por exemplo, indica que o sistema de planejamento para municípios acima de 20.000 habitantes, inicia-se pelo Plano Diretor Municipal. O autor aponta que o planejamento orçamentário municipal deve incorporar as diretrizes do referido Plano Diretor.

A existência e validade de processos de planejamento estratégico para municípios contemplando visão de futuro e vocação da cidade, também é apontada por Oliveira (2006, p. 11).

Outros setores da administração municipal devem também possuir seus documentos de planejamento estratégico setorial - tais como os planos municipais de saúde, os planos municipais decenais de educação e os planos municipais de assistência social.

Todos estes documentos possuem diretrizes macro-organizacionais (considerando a posição do município em um contexto com variáveis externas à administração local, tais como integração regional e inserção em sistemas federais de atuação) que devem interligar-se ao planejamento orçamentário municipal.

A integração deve buscar na contabilidade fundamento e meio de aplicação prática possibilitando que a contabilidade aplicada ao setor público seja uma ciência que cumpra sua função de origem, qual seja, a de um sistema de informações gerenciais que possibilite a tomada de decisão por parte de gestores e a provisão de informações a quaisquer de seus usuários (REIS e MACHADO JR, 2012; OLIVEIRA, 2006, p. 66; GRATERON, 199, p.6 - 7; RIBEIRO, 2013, p. 7 - 8; SILVA e CAVALCANTI, 2005, p. 4).

\section{METODOLOGIA}

A presente pesquisa foi realizada com base em estudos bibliográficos e documentais - estes disponibilizados em hipertexto por órgãos da administração pública tanto federal quanto municipal, bem como em experimentação pragmática do autor.

Dessa forma, foram utilizadas como base referencial obras da literatura técnica voltadas aos temas de administração pública e municipal, administração empresarial, contabilidade pública, planejamento e orçamento públicos e 
planejamento estratégico municipal.

Também o saber acadêmico disseminado por meio de trabalhos científicos compôs a base bibliográfica do estudo presente, materializando-se por consultas a artigos científicos e teses de mestrado versando sobre indicadores aplicados à gestão, orçamento-programa, indicadores de desempenho comumente utilizados na administração pública federal e avaliação de políticas públicas.

Ainda, documentos públicos com base na lei de acesso à informação e disponibilizados em ambiente virtual de amplo acesso público foram utilizados. Portanto, mostra-se o estudo como bibliográfico e documental.

Por estudar detalhadamente diversas nuances do objeto (permitindo que se desenvolva amplo e detalhado conhecimento) pode ser entendido, ainda, como estudo de caso.

Uma vez que o conhecimento produzido poderá ser replicado após a ocorrência dos fatos geradores originais (já que se trata de estudo calcado na experiência profissional do autor), pode o presente projeto ser visto como de pesquisa após o fato (ou expost-facto).

Quanto à natureza, possui características de pesquisa aplicada tendo por objetivo gerar conhecimentos para aplicação práticas de problemas específicos que envolvem interesses locais.

Por considerar a relação dinâmica entre o mundo real e o sujeito da pesquisa (associando objetividade à subjetividade do pesquisador), tendo por base a interpretação da realidade e atribuindo significados aos fenômenos observados, utilizando-se do ambiente natural para a coleta de dados e do pesquisados como elemento-chave do trabalho realizado, possui os elementos de pesquisa qualitativa.

Em relação aos objetivos, a presente peça pode ser entendida como pesquisa exploratória. Visa, portanto, proporcionar familiaridade com o problema para torná-lo explícito ou compreensível e para construir hipóteses. Comumente, envolve levantamento bibliográfico ou trata-se de estudos de caso (MEDEIROS et al., 2014, p. 70-74). 


\section{ANÁLISE E INTERPRETAÇÃO DOS DADOS}

A criação de indicadores padronizados de desempenho do planejamento orçamentário para a administração de pequenos e médios municípios deve considerar a utilização de informações contábeis para sua efetivação com êxito. Tal preocupação deriva, entre outros aspectos, da necessidade de que o custo de apuração do indicador seja significativamente menor que o benefício gerado.

Por isso, a estrutura de tecnologia de informação e comunicação existente no município necessita também ser considerada na criação e implementação de tais indicadores padronizados.

A utilização de relatórios extraídos do movimento contábil utiliza informações que são, a priori, fidedignas e passíveis de obtenção com fluidez, celeridade e utilidade para o usuário.

\subsection{BENEFÍCIOS DA PADRONIZAÇÃO DE INDICADORES}

A padronização de indicadores possibilita, para os órgãos centrais e agentes de decisão a comparação entre os centros de responsabilidade pela execução dos programas e ações de governo, a comparabilidade da atuação setorial e a visão da execução de cada programa de governo.

Por centros de responsabilidade deve-se entender cada órgão de governo responsável pela execução do programa e pela demonstração dos resultados obtidos.

A padronização permite que se possa realizar a comparação entre os resultados obtidos e recursos despendidos por cada órgão de execução. Propicia-se ao gestor, assim, a visão de resultados de cada programa de governo, do desempenho de cada órgão executor e a visão do resultado geral da atuação governamental.

É importante observar que os indicadores padronizados devem, inicialmente, focar a busca de informações de desempenho para cada programa de governo. Tal cuidado deve-se ao fato de que o objetivo da referida padronização é exatamente dispor aos agentes setoriais a oportunidade de conhecer e apropriar-se, com segurança e 
posterior autonomia, de ferramenta estatística e gerencial que prove ser útil à operacionalidade do setor, órgão ou secretaria municipal.

Conforme exposto anteriormente, a criação e o uso de indicadores factíveis e oportunos extrapolam o mero controle de estratégias e resultados, incidindo beneficamente sobre a motivação da equipe de trabalho envolvida.

\subsection{PADRONIZAÇÃO E SISTEMAS DE INDICADORES DA GESTÃO}

À medida que cada setor desenvolva conhecimento e metodologia e passe a utilizar os indicadores para a avaliação da execução dos programas de governo, tende-se que as informações geradas por cada indicador padronizado possam ser comparadas entre si.

A comparação entre os resultados apurados de cada indicador pode ser considerada o passo inicial para a criação de um sistema de indicadores de desempenho da gestão.

De mesma forma, a utilização inicial de indicadores padronizados deve reservar o cuidado de ser feita concomitantemente com, ao menos, um indicador de natureza setorial.

Isto se deve ao fato de que os indicadores padronizados buscam demonstrar informações gerais sobre os aspectos de cada programa de governo e possibilitar a comparação por meio de uma visão macro de atuação do ente governamental, tal como: execução financeira em confronto com a prevista, grau de aderência da execução física em comparação com a execução inicialmente prevista, entre outros.

Portanto, as características específicas de obtenção de resultados de cada programa necessitam ser apuradas e demonstradas por indicadores de programas setoriais.

Por exemplo, um indicador de permanência escolar deve ser utilizado para um programa de governo para a área educacional. Não poderia ser apurado e demonstrado para programas de governo de infraestrutura. Portanto, índice de permanência escolar não pode ser utilizado como indicador padronizado de desempenho da gestão do ente federativo. 
Por outro lado, tal indicador reflete com clareza se o programa de governo está obtendo resultados na resolução de um problema social voltado à escolarização e alfabetização. Dessa forma, deve ser utilizado conjuntamente com indicadores padronizados para que possa refletir se o resultado obtido guarda correlação com visão macro da administração.

\subsection{CARACTERÍSTICAS PARA INDICADORES PADRONIZADOS}

Embora, em casos estritos, possam ser utilizados indicadores operacionais, deve-se saber que o foco da medição refere-se à gestão do programa de governo (entendido como um conjunto de ações organizadas para o atingimento de determinado objetivo). É imprescindível evitar, portanto, indicadores para cada ação isoladamente. Por conceito, cada ação é medida por metas físicas e financeiras - e não por indicadores.

Faz-se importante atentar para que os indicadores personalizados guardem a forma de relações comparativas entre fatores - evitando que valores numéricos absolutos sejam confundidos como indicadores.

$\mathrm{Na}$ técnica orçamentária-programática, cada ação que compõe o programa de governo possui uma unidade de medida composta por valor absoluto, medindo a execução "física" de cada ação.

Deve-se, dessa forma, tomar o cuidado de incidir a padronização de indicadores financeiros somente sobre o movimento de cada programa. Assim sendo, os indicadores devem trazer como fatores valores indicativos do resultado concreto da execução do programa.

Nada obsta que se realize a comparação em termos físicos e financeiros de cada ação, desde que restrito ao exercício financeiro e desde que tal comparação não se torne a matriz de orientação programática. O gestor deve preocupar-se em atingir os objetivos do programa de governo. As ações que compõem cada programa não possuem objetivos - possuem metas físicas medidas por unidades e para cada qual existe um custo previamente fixado.

Por objetivos de programa de governo, deve-se entender o resultado pretendido 
para resolver um determinado problema social. Por exemplificação, um problema social pode ser a baixa qualidade do ensino em determinado município. Evidentemente, para aumentar a qualidade do ensino não basta apenas ter ações de construção de escolas. Outras ações precisam ser realizadas em conjunto, tais como reforma das escolas já existentes, distribuição de atendimento escolar por zonas geográficas, transporte escolar, merenda para alunos, valorização de profissionais envolvidos na atividade educacional, entre outros. O agrupamento organizado e a execução concatenada de todas essas ações comporão um programa de governo cujo objetivo será a melhoria da qualidade do ensino.

Para este programa, indicadores tais como taxa de evasão escolar, taxa de aprovação poderão ser utilizados. Cita-se, para este caso, o Indicador de Desempenho da Educação Básica (IDEB) como referência obrigatória contemporânea.

Os indicadores padronizados, para o caso exposto, deverão medir a resolução do problema social - ou, em outros termos, o alcance do objetivo do programa de governo.

\subsection{A CONSTRUÇÃO DE INDICADORES PADRONIZADOS}

Toda a sistemática de elaboração e utilização de indicadores programáticos, portanto, deve pautar-se pela medição dos resultados de programas de governo.

Dessa forma, pode-se realizar análise comparativa entre o inicialmente previsto e o efetivamente realizado em termos de execuções global financeira e física, por exemplo. Nessa linha de análise, o confronto entre a previsão financeira e sua respectiva realização possibilita a visão de eficiência e grau de economicidade da gestão programática e de operacionalidade, gerando indicadores de "execução financeira do programa" e "grau de cumprimento do planejamento".

De mesma forma, indicador de "grau de eficiência na captação e utilização de recursos de terceiros" (tais como de acordos voluntários de transferência de recursos ou de firmamento de operações de crédito) indicam, por exemplo, a atuação do setor na utilização de recursos obtidos junto aos demais entes federativos. 
Esses recursos podem ser, por exemplo, acordos voluntários para transferências financeiras ou contratação de operações de crédito. Aqueles são os chamados "convênios" ou termos de repasse e estes são os empréstimos bancários. Ambos são vinculados a objetos e gastos especificados em termo de contrato entre as partes.

A cooperação técnica e financeira, inclusive, constitui meio de fortalecimento do pacto federativo e abre interessante campo de atuação governamental - sobretudo para a administração municipal.

Essa cooperação possibilita ampliação da atuação pública sem onerar a capacidade de geração de receita própria.

De mesma forma, tal atuação profícua lança mão das oportunidades possibilitadas pelos sistemas federais de gestão compartilhada de políticas públicas - sobretudo para as funções educacionais, de saúde e de assistência social.

Indicadores de processos administrativos - tais como de fluxo de documentos, propiciam a visualização do tempo de resposta, bem como de acúmulo documental no âmbito da organização. A geração de estoques processuais, de aumento do tempo de resposta ou de incremento da geração documental pode indicar necessidade de alteração ou aprimoramento de rotinas administrativas, de necessidade de capacitação de pessoal ou de aprimoramento tecnológico. Tal indicador pode ser apurado por relatórios de sistema digital de controle de documentos ou, em último caso, por conferência manual em livro de registro.

\begin{tabular}{|c|c|c|c|c|}
\hline Nome & Medida & Fórmula de Cálculo & Fonte de Dados & Perspectiva \\
\hline Execução Financeira & Taxa & $\begin{array}{l}\text { Execução Orçamentária } \\
\text { Previsão Orçamentária }\end{array}$ & $\begin{array}{l}\text { Previsões: Plano Plurianual } \\
\text { Execução: Demonstrativos Contábeis }\end{array}$ & $\begin{array}{l}\text { Orçamentária e } \\
\text { Financeira }\end{array}$ \\
\hline $\begin{array}{l}\text { Grau de Cumprimento do } \\
\text { Planejamento }\end{array}$ & Taxa & $\frac{\text { Total Físico Executado }}{\text { Total Físico Previsto no PPA }}$ & $\begin{array}{l}\text { Previsões: Plano Plurianual } \\
\text { Execução: Relatórios Setoriais de Metas }\end{array}$ & $\begin{array}{l}\text { Planejamento de } \\
\text { Metas }\end{array}$ \\
\hline $\begin{array}{l}\text { Eficiência na Captação de } \\
\text { Recursos de Terceiros }\end{array}$ & Taxa & $\frac{\text { Execução Orçamentária de Recursos de Terceiros }}{\text { Recursos de Terceiros Previstos }}$ & $\begin{array}{l}\text { Previsões: Plano Plurianual } \\
\text { Execução: Demonstrativos Contábeis }\end{array}$ & $\begin{array}{l}\text { Orçamentária e } \\
\text { Financeira }\end{array}$ \\
\hline Fluxo Processual & Taxa & $\frac{\text { Total de Processos Remetidos ou Despachados }}{\text { Total de Processos Recebidos }}$ & $\begin{array}{l}\text { Sistema Informatizado de Protocolo ou } \\
\text { Conferência Manual }\end{array}$ & Administrativa \\
\hline Incremento Processual & Taxa & $\begin{array}{l}\text { Total de Processos Protocolados no Período } \\
\text { Total de Processos Protocolados no Período Anterior }\end{array}$ & $\begin{array}{l}\text { Sistema Informatizado de Protocolo ou } \\
\text { Conferência Manual }\end{array}$ & Administrativa \\
\hline
\end{tabular}

Figura 3: Indicadores Padronizados em Plano Plurianual 2014 a 2017

Fonte: Cachoeiro de Itapemirim, 2013.

ianual

2014 a 2017 do Município de Cachoeiro de Itapemirim. Para tais indicadores foi perceptível a utilização de taxas como forma de comparativo da parcela sobre o total apurado. 
O indicador de execução financeira do programa busca demonstrar a execução financeira dos programas em confronto com o previsto inicialmente no plano plurianual, permitindo ao gestor a visão de previsão e execução de gastos para a realização das políticas públicas planejadas.

Quanto ao indicador de grau de cumprimento do planejamento, buscou-se possibilitar ao gestor a visão de execução física do programa. Assim sendo, pode-se entender tal indicador como de demonstração da operacionalidade do programa em termos de realização de metas físicas.

O comparativo entre os indicadores de execução financeira e de cumprimento do planejamento torna possível ao gestor perceber se a execução de metas guarda correlação com os gastos previstos inicialmente. O comparativo de tais resultados, dessa forma, torna possível a gestão dos gastos por realização de metas programáticas.

O índice de eficiência na captação de recursos oportuniza ao gestor o acompanhamento e aprimoramento dos mecanismos institucionais de busca de parcerias e de captação de recursos para a realização de políticas públicas. 0 resultado de tal indicador aponta o grau de aproveitamento das oportunidades de maximização da atuação da entidade governamental por meio de utilização de financiamentos contratuais ou apropriação de recursos de outras esferas de governo (tais como convênios, repasses ou parcerias para realização de objetivos comuns).

Os indicadores padronizados acima partem da perspectiva de planejamento de metas, orçamento e finanças - medindo, em grande parte, a execução física e financeira do plano de metas de médio prazo, fornecendo ao gestor a visão de operacionalidade e eficiência interna da organização.

A resolução de problemas sociais e a efetividade das políticas públicas devem, conforme já mencionado, serem medidas e avaliadas por meio da utilização de indicadores setoriais personalizados - os quais devem refletir se os programas de governo estão obtendo resultados favoráveis para a resolução de problemas sociais - estes expostos em forma de objetivos de cada programa orçamentário.

Quanto aos indicadores de fluxo e incremento processual, fornecem ao gestor a percepção da capacidade administrativa de cada setor organizacional. Baseado na 
capacidade da organização em movimentar processualmente as demandas recebidas, oportuniza ao gestor perceber situações tais como a movimentação interna de documentos, tempo de resposta e existência ou não de estoques de documentos. A análise de tais situações pode resultar em identificação de gargalos organizacionais e promover a busca pela causa de tais situações - que pode ser desde a necessidade de melhoria de infraestrutura física até situações de motivação interna de servidores ou colaboradores da organização.

Conforme perceptível pela coluna de fontes de dados, a construção dos referidos indicadores buscou adequação à possibilidade de apuração considerando as características da organização.

[...]o objetivo é dotar a administração pública municipal local de instrumentos de medição que indiquem a situação contemporânea de programas previstos no plano plurianual por meio de instrumentos que possam ser utilizados dentro das capacidades tecnológica do município e de conhecimentos aplicáveis dos órgãos setoriais de execução dos programas e ações. (sic) (CACHOEIRO DE ITAPEMIRIM, 2013a, p. 2)

A construção dos indicadores elencados à Figura 3 demonstra, primariamente, 0 sistema de financiamento do planejamento, bem como a preocupação na verificação do cumprimento de metas. Indica, portanto, atuação voltada busca por parcerias voluntárias ou contratuais como forma de aumento da capacidade de atendimento da demanda social, bem como de utilização de conhecimentos e rotinas que permitam monitoramento e avaliação do plano plurianual. Tal realinhamento capacita o retorno das ações governamentais ao plano inicial, adequando-se às mudanças reais de cenários econômicos. (CACHOEIRO DE ITAPEMIRIM, 2013b, p. 15 e 17).

A análise dos resultados dos indicadores pode ser feita de forma segmentada, agrupada ou consolidada. Por aquele prisma, os indicadores fornecem ao gestor a visão do desempenho de cada programa.

A partir do ponto em que são correlacionados por órgão ou setor, evidenciam o desempenho setorial na execução do planejamento de políticas públicas e programas de governo.

Pela consolidação dos dados, os indicadores correlacionados permitem ao gestor apropriar-se da visão ampla da atuação organizacional e do nível de adequação às 
metas do planejamento inicial. Em seguimento, aponta possível necessidade de correções de execução ou realinhamento de atuação para que os objetivos iniciais possam ser atingidos.

O cruzamento das informações de tais indicadores padronizados junto a demais medições de caráter amplo permite à gestão entregar à sociedade os resultados de seus objetivos macros de planejamento.

A padronização de indicadores de desempenho e gestão deve considerar os custos e os esforços envolvidos. Assim sendo, a elaboração e apuração dos mesmos deve agregar qualidade à gestão, não sendo meramente procedimento formal.

Pode-se citar como referência o trabalho executado pelo Tribunal de Contas da União intitulado Portfólio de Indicadores utilizados na Administração Pública no Brasil e no exterior (BRASIL, 2014?), exemplificado pela Figura 4.

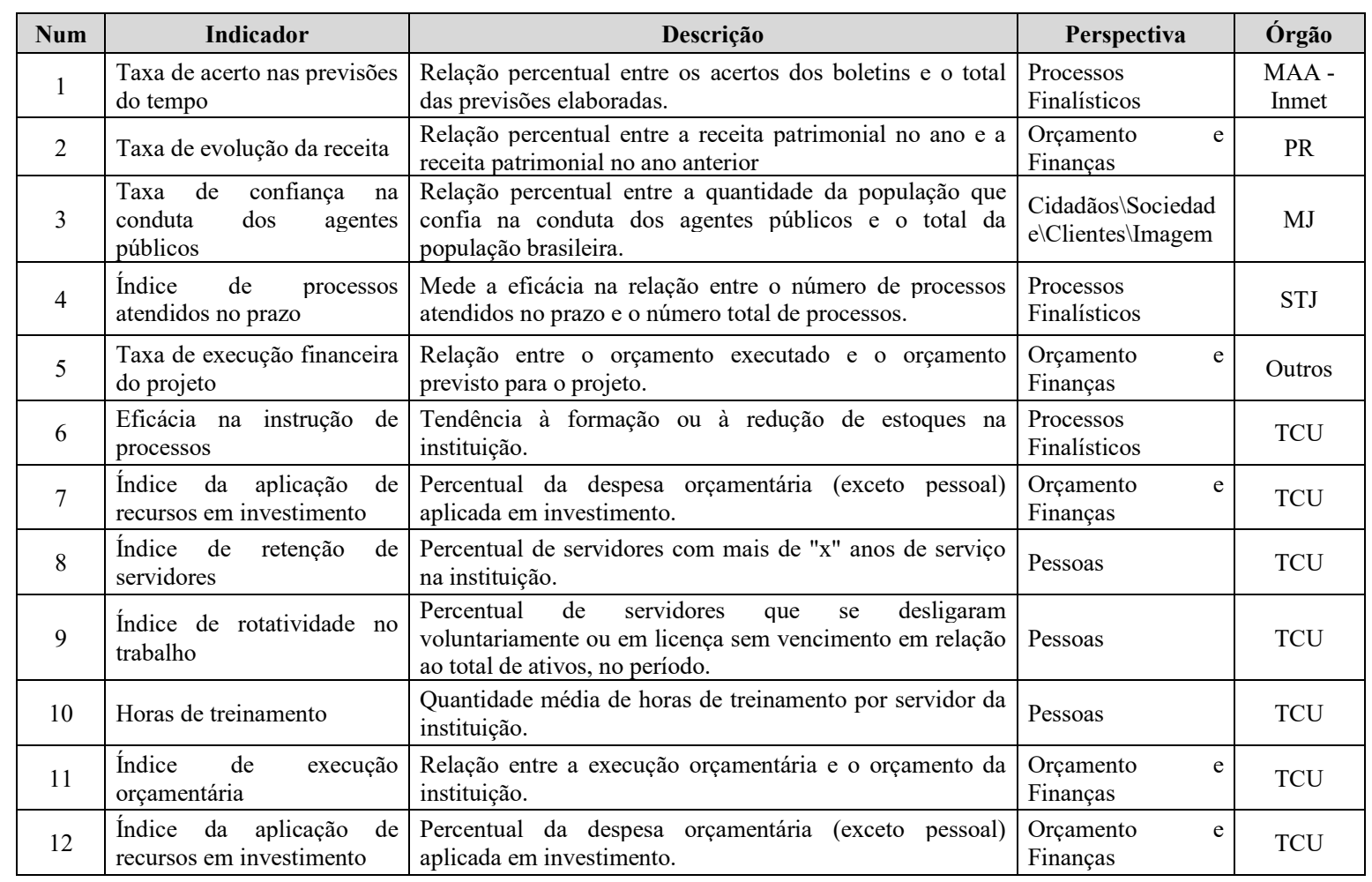

Figura 4: Indicadores utilizados na Administração Pública Fonte: Brasil, 2014?

A utilização de indicadores conforme tal documento confere à padronização local caráter de consistência - haja vista tratar-se de índices utilizados comumente por órgãos de referência da administração federal. Novamente ressalta-se a interpretação e adaptação de tais indicadores às realidades locais para que possam ser utilizados de forma qualitativa e apurados conforme a boa técnica de gestão, 
considerando as capacidades tecnológicas e o conhecimento existente em cada organização administrativa pública municipal.

\section{CONSIDERAÇÕES FINAIS}

A prática da gestão administrativa deve considerar a utilização de sistemas de indicadores de desempenho como forma de apuração dos êxitos das políticas públicas.

Toda organização possui um sistema, considerado em conceito primário, composto de entradas ou insumos, processamentos ou atividades e produtos ou resultados. Dadas as características peculiares da administração governamental, os resultados necessitam ser considerados além da mera geração de utilidade econômica - por isso, a medição de desempenho na administração pública revela-se procedimento de caráter complexo dados os impactos das ações do governo sobre a sociedade por períodos longos de tempo.

Nesse diapasão, a menor capacidade tecnológica, técnica e de conhecimento atinentes às administrações municipais face aos demais entes da federação inclusive com a existência de realidades locais multíplices e individualizadas, torna a utilização de sistemas de medição de desempenho da gestão um processo ainda a ser desenvolvido em grande parte dos municípios brasileiros.

Tal realidade é refletida também pelos estudos acadêmicos, mais voltados à formação de agendas e elaboração de políticas públicas do que ao seu controle, avaliação e monitoramento . Se por um lado tais dificuldades se fazem presente, por outro tornam ainda mais oportuna a utilização de indicadores padronizados de desempenho da gestão municipal.

Dessa forma, o presente estudo demonstrou a admissibilidade de utilização de instrumentos de medição do desempenho tanto na administração empresarial quanto na gestão das organizações públicas - uma vez que ambas se situam no campo da administração enquanto ciência.

Foi possível demonstrar que a correlação entre entidades do setor público e do setor privado faz-se pelo critério de racionalidade na alocação de recursos, diferenciando- 
se ambas apenas pela percepção do que seja racionalidade. Esta percepção deriva dos objetivos distintos a serem atingidos pelas organizações de cada campo administrativo.

Foi possível propor a construção de indicadores padronizados de resultados como passo inicial para a formação posterior de sistema de informações de gestão para municípios de pequeno e médio porte brasileiros.

Foi demonstrado que tal construção pode utilizar-se da experiência já vivenciada por demais órgãos públicos, sendo proposto como referencial os indicadores constantes do portfólio de indicadores utilizados na administração pública federal.

Por fim, percebeu-se que a utilização de ferramentas padronizadas de gestão, além de promover o suporte à tomada de decisão, gera efeito benéfico sobre as pessoas envolvidas no processo de elaboração, execução e avaliação de programas e orçamentos de governo - proporcionando o desenvolvimento do conhecimento e da inteligência organizacional.

\section{REFERÊNCIAS}

ANDRADE, Nilton de Aquino (Org.) [et al.]. Planejamento Governamental para Municípios. Plano Plurianual, Lei de Diretrizes Orçamentárias e Lei Orçamentária Anual. - 2a . Ed. - São Paulo: Atlas, 2008.

BRASIL. TCU. Portfólio de Indicadores adotados por instituições públicas no Brasil e no exterior para mensuração de desempenho. [2014?]. Disponível em: <http://www.tcu.gov.br/Portfoliolndicadores> Acesso em: 08 set 2015.

\section{. TCU. Relatório Resumo do IV Congresso Internacional de}

Contabilidade. Relatório desenvolvido pelo Auditor Federal de Controle Externo do Tribunal de Contas da União Célio da Costa Barros, 2010. Disponível em:<http://portal2.tcu.gov.br/portal/page/portal/TCU/comunidades/educacao corpora tiva/disseminacao conhecimento/RELAT\%C3\%93RIO - RESUMO IV\%20\%20Congresso\%20ANPCONT.pdf > Acesso em: 29 fev 2012.

CACHOEIRO DE ITAPEMIRIM (MUNICÍPIO). Indicadores padrão mínimos para o plano plurianual. Estudo para utilização de indicadores padrão mínimos de desempenho para os programas do PPA 2014 a 2017. Cachoeiro de Itapemirim: 2013.

Plano Plurianual Cachoeiro de Itapemirim PPA 2014 a 2017. Publicado no Diário Oficial do Município $n^{\circ} 4503,2013$. Disponível em:

<http://www.cachoeiro.es.gov.br/transparencia> Acesso em 17 nov 2015. 
FERNANDES, Djair Roberto. Uma contribuição sobre a construção de indicadores e sua importância para a gestão empresarial. Revista da FAE, Curitiba, v.7, p. 118, jan/jun. 2004. Disponível em: <

http://www.fae.edu/publicacoes/pdf/revista da fae/fae v7 n1/rev fae v7 n1 01 dej air.pdf > Acesso em: 05 mar 2015.

FREZATTI, Fábio et al . Análise do relacionamento entre a contabilidade gerencial e o processo de planejamento das organizações brasileiras. Rev. adm. contemp., Curitiba, v. 11, n. spe2, p. 33-54, 2007. Disponível em: < http://www.scielo.br/scielo.php?script=sci arttext\&pid=S1415-655520070006 $\underline{00003 \& \operatorname{lng}=e n \& n r m=i s o}>$. Acesso em: 17 jun 2015.

GRATERON, Ivan Ricardo Guevara. Auditoria de gestão: utilização de indicadores de gestão no setor público. Caderno de estudos, $n^{\circ} 21$, São Paulo, maio/ago,1999. Disponível em:

<http://www.eac.fea.usp.br/cadernos/completos/cad21/auditoria.pdf>. Acesso em: 12 mar 2015.

KERBAUY, Maria Teresa Miceli. As câmaras municipais brasileiras: perfil de carreira e percepção sobre o processo decisório local. Opin. Publica, Campinas, v. 11, n. 2, p. 337-365, Oct. 2005. Disponível em: < http://www.scielo.br/scielo.php? script=sci arttext\&pid=S0104-62762005000200003\&Ing=en\&nrm=iso>. Acesso em: 04 Ago. 2015.

MARTINS, Marco Antônio dos Santos. Construção de Indicadores para avaliação do desempenho empresarial. Dissertação de Mestrado apresentada ao Programa de Pós - Graduação em Economia da Universidade Federal do Rio Grande do Sul. 2004. Disponível em: <http://hdl.handle.net/10183/4675> Acesso em: 12 mar 2015.

OLIVEIRA, Gecileno Luiz de. Integração entre os Instrumentos de Planejamento Orçamentário de Políticas Públicas. Trabalho científico apresentado á Universidade Gama Filho - UGF e disponibilizado na Biblioteca Digital Portal Domínio Público do Ministério da Educação do Brasil, Cachoeiro de Itapemirim, 2006. Disponível em:

<http://www.dominiopublico.gov.br/download/texto/ea000924.pdf> Acesso em: 12 mar 2015.

OLIVEIRA, Gecileno Luiz de. POUBEL DA SILVA, M.A. O relatório anual de avaliação do plano plurianual frente à atuação da câmara municipal: existe possibilidade de rejeição? Artigo científico disponibilizado na Biblioteca Virtual Sobre Corrupção da Controladoria Geral da União. Out-2012. Disponível em: <http://bvc.cgu.gov.br/handle/123456789/3746> Acesso 11 mar 2015.

RAMOS, Marília Patta e SCHABBACH, Letícia Maria. O estado da arte da avaliação de políticas públicas: conceituação e exemplos de avaliação no Brasil. Rev. Adm. Pública [online]. 2012, vol.46, n.5, pp. 1271 - 1294. ISSN 00347612. Disponível em <http://www.scielo.br/scielo.php?script=sci arttext\&pid=S003476122012000500005> Acesso em: 31 out 2012.

REZENDE, Denis Alcides; CASTOR, Belmiro Valverde Jobim. Planejamento Estratégico Municipal. Empreendedorismo participativo nas cidades, prefeituras e organizações públicas. Rio de Janeiro: Brasport, 2005. 
REZENDE, Denis Alcides. Planejamento de informações públicas municipais: sistemas de informação e de conhecimento, informática e governo eletrônico integrados aos planejamentos das prefeituras e municípios. Rev. Adm. Pública, Rio de Janeiro , v. 41, n. 3, p. 505-536, jun. 2007 . Disponível em $<$ http://www.scielo.br/scielo.php?script=sci arttext\&pid=S0034-

76122007000300007\&lng=pt\&nrm=iso>. acessos em 17 nov. 2015.

REIS, Heraldo da Costa. MACHADO JR, José Teixeira. A lei 4.320 comentada e a lei de responsabilidade fiscal. $34^{a}$ ed., rev. Ed. atual. - Rio de Janeiro: Lumen Juris, 2012.

RIBEIRO, Darcy Marzulo. O orçamento-programa como instrumento de gestão pública. Cad. IPARDES, Curitiba, PR, e ISSN 2236-8248, v. 3, n. 2, p. 1-24 jul./dez. 2013. Disponível em: < http://www.ipardes.pr.gov.br/ojs/index.php/cadernoipardes/ article/view/652/870> Acesso em: 05 mar. 2015.

SILVA, O. G.; CAVALCANTI , A. L. C. Uma análise dos indicadores de gestão utilizados no setor público federal no Brasil. Trabalho desenvolvido no curso de Graduação de Ciências Contábeis da Universidade Católica de Brasília (UCB) , 2005. Disponível em: <http://www.contabeis.ucb.br/sites/000/96/00000098.pdf>. Acesso em: 09 mar. 2015. 